\title{
Correction to: Influence of iron mining activity on heavy metal contamination in the sediments of the Aqyazi River, Iran
}

\author{
Behzad Shahmoradi • Sahar Hajimirzaei • Jamil \\ Amanollahi $\cdot$ Kitirote Wantala $\cdot$ Afshin Maleki \\ Seung-Mok Lee • Moo Joon Shim (iD
}

Published online: 1 August 2020

(C) Springer Nature Switzerland AG 2020

\section{Correction to: Environ Monit Assess (2020) 192:521 https://doi.org/10.1007/s10661-020-08466-0}

The original version of this article unfortunately contained an error in the affiliation section and missing acknowledgment statement.

The city "Erbil" that was included in the affiliation of the third author (Jamil Amanollahi) should be changed to "Sanandaj". The corrected affiliation 2 is shown below.

The added acknowledgement statement is also shown below.

The online version of the original article can be found at https://oi. org/10.1007/s10661-020-08466-0

B. Shahmoradi $\cdot$ S. Hajimirzaei $\cdot$ A. Maleki

Environmental Health Research Center, Research Institute for Health Development, Kurdistan University of Medical Sciences, Sanandaj, Iran

B. Shahmoradi

e-mail: bshahmorady@gmail.com

\section{S. Hajimirzaei}

e-mail: saharmirzay@yahoo.com

A. Maleki
e-mail: maleki43@yahoo.com
Acknowledgements The authors would like to thank Kurdistan University of Medical Sciences, Sanandaj, Iran for providing financial supports under Grant Number: 1395/45. This study was also partially supported by International Affairs Division of Khon Kaen University (International Visiting Scholar, 2019 for Assoc. Prof. Behzad Shahmoradi).

Publisher's note Springer Nature remains neutral with regard to jurisdictional claims in published maps and institutional affiliations.

\section{J. Amanollahi}

Department of Environmental Science, Faculty of Natural Resources, University of Kurdistan, Sanandaj, Iran e-mail: j.amanollahi@uok.ac.ir

\section{K. Wantala}

Department of Chemical Engineering, Faculty of Engineering, Khon Kaen University, Khon Kaen, Thailand e-mail: kitirote@kku.ac.th

S.-M. Lee $(\bowtie) \cdot$ M. J. Shim $(\bowtie)$

Department of Environmental Engineering, Catholic Kwandong University, Gangneung 25601, South Korea

e-mail: leesm@cku.ac.kr

e-mail: moojoonshim@gmail.com 